\title{
Picking nannofossils: How and why
}

\author{
Baptiste Suchéras-Marx $^{1 *}$, Fabienne Giraud ${ }^{2,3}$, Alex Lena ${ }^{4,5}$ \& Alexandre Simionovici ${ }^{2,3}$ \\ ${ }^{1}$ Aix-Marseille University, CNRS, IRD, CEREGE UM34, 13545 Aix-en-Provence, France \\ ${ }^{2}$ University of Grenoble Alpes, ISTerre, CS 40700, 38058 Grenoble Cedex, France \\ ${ }^{3}$ CNRS, ISTerre, F-38058 Grenoble, France \\ ${ }^{4}$ Direction de la Recherche et des Études Doctorales, Université Claude Bernard Lyon 1, Campus de la Doua, \\ 69622 Villeurbanne Cedex, France \\ ${ }^{5}$ UMR CNRS 5276 LGL, Université Claude Bernard Lyon 1, Ecole Normale Supérieure Lyon, Campus de la Doua, \\ 69622 Villeurbanne Cedex, France \\ *Correspondence: sucheras-marx@cerege.fr
}

Received 29 March 2016; revised 2 June 2016; accepted 2 June 2016

Calcareous nannofossils are a group of micrometric fossils abundantly found in marine sediments. This group is mainly composed of coccoliths, platelets produced by the unicellular algae coccolithophores, and nannoliths whose biological affinity remains unknown. Calcareous nannofossils have a continuous record for the past 215 myr (Bown 1998) and can be found in almost every marine environment from coast to open oceans and from the Equator to the poles in surface waters (Winter et al. 1994). These microfossils are also made of low-Mg calcite (Siesser 1977; Stoll et al. 2001) which is resistant to dissolution and a common matrix for geochemical analyses in palaeoceanography. Hence, calcareous nannofossils could be one of the best fossils for palaeoceanographical studies for the last 215 myr. Their use in geochemistry is, however, less common than planktic foraminifera due to their small sizes, masses $(10-1000 \mathrm{pg})$ and complex vital effects. Despite the fact that nannofossils are very small $(2-20 \mu \mathrm{m})$, the development of highresolution analytical devices opens up the opportunity to analyse single nannofossils or even parts of them. This is a growing field of nannofossil research.

In order to overcome this challenging issue, many methods have been developed to isolate nannofossils from the matrix or as single specimens such as filtration (Minoletti et al. 2009), settling velocity (Stoll \& Ziveri 2002), flux cytometry (Halloran et al. 2009) or micromanipulator-assisted picking (Stoll et al. 2007; Stoll \& Shimizu 2009). Among the different methods cited, the picking method is the best selective method although it is more time consuming than the others for isolating the same amount of nannofossils. The picking method developed by Stoll \& Shimizu (2009) is also expensive in equipment because it strictly depends on a micromanipulator and an inverted microscope.

In this Notebook, we present an alternative picking method that does not require a pricey micromanipulator or inverted microscope and can be used by the majority of the nannofossil community. Alongside the presentation of the method, we also present the range of applications of the method in its current form.

\section{Picking method}

The protocol presented here is a basic hand-picking method. This hand-picking requires (1) a microscope with $\times 40$ and $\times 10$ objectives and linear polarization filters; (2) silica capillaries of $50 \mu \mathrm{m}$ internal diameter; (3) pure ethanol; and (4) a sample holder to deposit the picked nannofossils (e.g. $\mathrm{Si}_{3} \mathrm{~N}_{4}$ TEM windows, Ultralene ${ }^{\circledR}$ window film). The sample holder depends on the analytical device used.

\section{Preparation of the silica (Si) spine}

Silica capillaries are used for the picking itself in the form of a Si spine. We used Polymicro Technologies ${ }^{\mathrm{TM}}$ capillary tubing made of a $\mathrm{Si}$ microtube of $50 \mu \mathrm{m}$ internal diameter coated with polyimide resulting in a $150 \mu \mathrm{m}$ outer diameter of the capillary. In order to prepare the $\mathrm{Si}$ spine, a capillary should be heated in a butane flame for a few seconds; the coating will be burned out and the Si melted. Once melted, the Si capillary should be stretched out until it breaks in two. Then the extremity should be cut at c. 15-20 $\mu \mathrm{m}$ external diameter (Fig. 1a, b). Once the capillary is thinned, users should fix it to a handle in order to facilitate the manipulation. We have used pipette tips because they are light but solid. The thinned capillary is placed in the aperture of the pipette tip, held with tack and fixed with liquid glue.

The Si spines should be manipulated with caution. They are very thin, hence they can easily penetrate the skin or plastic gloves, but are also brittle and very difficult to extract from the skin with clamps. They are made of $\mathrm{Si}$ and thus difficult to dissolve. We consider that is it almost impossible to extract a Si spine once it has penetrated the skin.

\section{Nannofossil slide preparation and microscope set up}

Prior to the picking, one can use any physical or chemical treatment, such as sieving to eliminate clays (e.g. Minoletti et al. 2009) or bleaching to eliminate organic matter (e.g. Blanco-Ameijeiras et al. 2012). Picking is undertaken from a standard nannofossil smear slide or gravity settling slide (Bown \& Young 1998) using a cover slide but without fixing it to a slide. Both techniques produce a monolayer of nannofossils on a cover slide. Prior to the picking, users should carefully dry the cover slide. If it is slightly wet, the picking is impossible. In order to hold and reinforce the cover slide, we recommend fixing it with tape or tack to a slide with the face holding the nannofossil up (Fig. 2a). It is also possible to make the standard nannofossil smear slide directly on a slide rather than on a cover slide.

The picking is made under a standard microscope having at least $\times 10$ and $\times 40$ objectives without immersion, linear polarizer and linear analyser. If possible, having a $\lambda / 4$ gypsum filter and a $\times 100$ objective without immersion helps nannofossil selection prior to picking.

\section{Picking and transferring nannofossils to a sample holder}

The picking itself is made manually, without using a micromanipulator. The nannofossil cover slide is placed under the microscope 

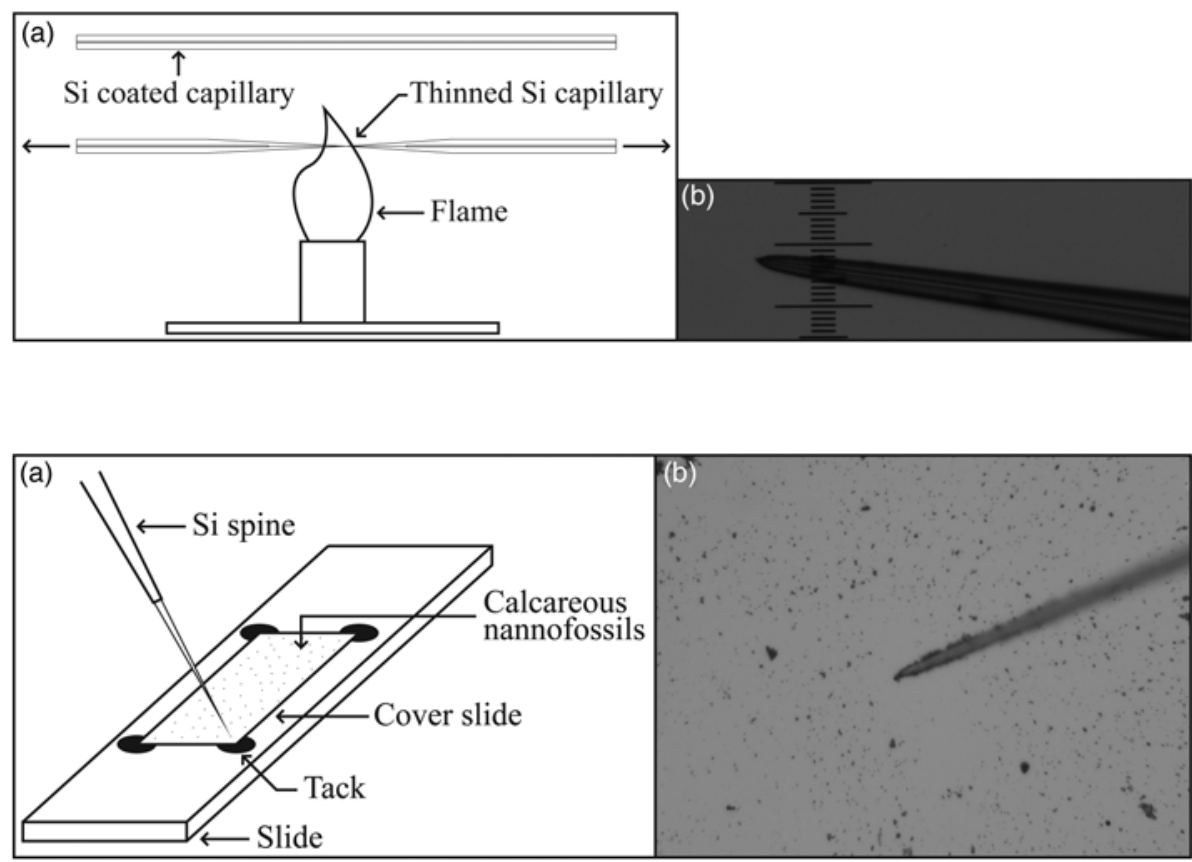

Fig. 1. Si spine preparation. (a) Sketch showing how to stretch a capillary down to $c .15-20 \mu \mathrm{m}$ using a butane flame. (b) Example of convenient size of Si spine (magnification $\times 100$ ) - large with a short end for easy use. Scale: 1 division $=$ $10 \mu \mathrm{m}$.

Fig. 2. Picking nannofossils. (a) Sketch presenting the cover slide and slide set-up for picking nannofossils. (b) Photograph during nannofossil picking (magnification $\times 100)$. with the $\times 40$ or $\times 100$ objective in order to select a nannofossil specimen for picking. Once selected, users should move to a $\times 10$ objective in order to have enough working space between the slide and the objective to pick. The user picks the nannofossils using the Si spine (Fig. 2a, b). If both cover slide and Si spine are dry, when the $\mathrm{Si}$ spine touches the nannofossil it will naturally stick to the spine because of electrostatic forces. With the nannofossil secured by electrostatic forces, another force is needed to detach it. We put a droplet of ethanol on the sample holder and brush the Si spine from back to front in order to hold the nannofossil in the ethanol by the surface tension of the droplet (Fig. 3a). This procedure might need repeating several times. A liquid other than ethanol (e.g. water) can be used depending on the purpose of the picking, the composition of the sample holder or the method used for the analysis. Eventually, the nannofossil will be isolated and the ethanol droplet will
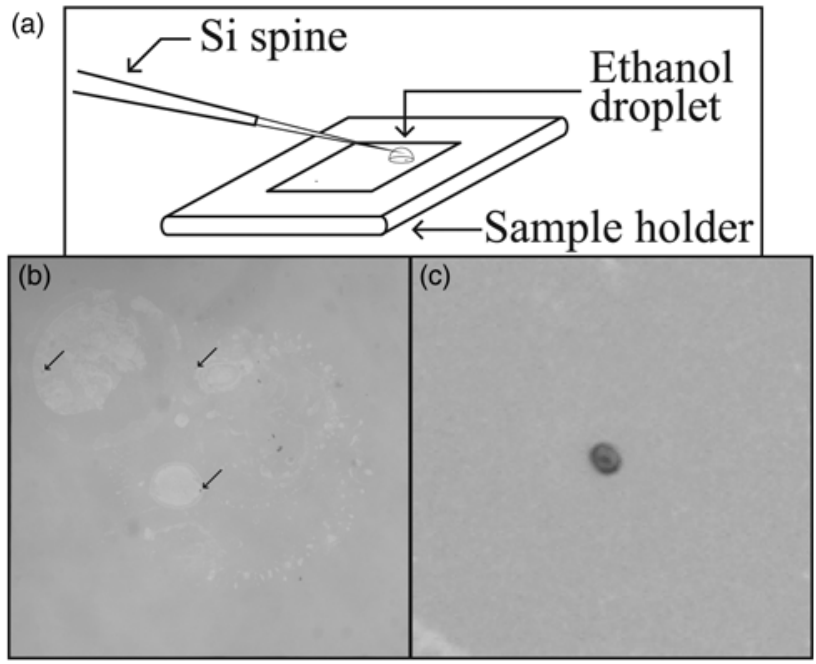

Fig. 3. Transfer of a nannofossil specimen to a sample holder. (a) Sketch presenting the transfer of a nannofossil specimen to a sample holder. (b) Photograph of a sample holder after nannofossil deposition (magnification $\times 100$ ). Black arrows show the calcareous nannofossil positions. Wide traces on the sample holder are made by the ethanol. (c) Photograph of picked Watznaueria britannica on a sample holder. The nannofossil specimen is 5-6 $\mu \mathrm{m}$ long. evaporate (Fig. 3b). Depending on the sample holder, the user can control the success of picking with an optical microscope (Fig. 3b) or an environmental scanning electron microscope.

In published (Suchéras-Marx et al. 2016) and unpublished studies using this picking method to isolate a single specimen, we have been able to isolate Calcidiscus leptoporus, Coccolithus pelagicus, Gephyrocapsa oceanica and Helicosphaera carteri from core-tops samples and Crepidolithus crassus, Cribrosphaerella ehrenbergii, Cyclogelosphaera margerelii, Discoaster araneus, Discoaster spineus, Discorhabdus striatus, Watznaueria barnesiae and Watznaueria britannica from land section samples. We encountered difficulties isolating Emiliana huxleyi because it is too small to be clearly identified under a $\times 40$ objective. Hence, for nannofossils with a length below $3 \mu \mathrm{m}$, we recommend using a $\times 100$ objective without immersion and a thinner Si spine, around $7-10 \mu \mathrm{m}$ external diameter.

\section{Reasons for using the picking method for sample preparation and concluding remarks}

We present here a non-exhaustive list of potential analyses and equipment that may need the picking method for sample preparation. The picking method presented in this manuscript has been used only for nanoscale XRF in Suchéras-Marx et al. (2016):

- high-resolution nannofossil tomography - nanoscale computed tomography scan (CT scan), focused ion beam-scanning electron microscopy (FIB-SEM, Hoffmann et al. 2015);

- single nannofossil crystallography - Raman spectroscopy, atomic force microscopy (AFM, Henriksen et al. 2003), electron back-scattered diffraction (EBSD, Saruwatari et al. 2008);

- small nannofossil population geochemistry - secondary ion mass spectrometry (SIMS, Stoll et al. 2007; Prentice et al. 2014);

- single nannofossil elemental and isotopic geochemistry nanoscale secondary ion mass spectrometry (NanoSIMS, Rickaby et al. 2004), nanoscale X-ray fluorescence (XRF, Suchéras-Marx et al. 2016), X-ray absorption near edge structure (XANES) and extended X-ray absorption fine structure (EXAFS). 
The picking method presented here is less effective than other published picking methods (Stoll et al. 2007; Stoll \& Shimizu 2009). We consider that about 5 nannofossils can be picked per hour which is far from the 15 coccoliths per 30-60 min in Stoll et al. (2007). We recommend the picking method presented here for analysis focusing on single to few individuals when small amounts of nannofossils are needed or when investment in expensive equipment, such as inverted-microscopy and micromanipulator, is not possible. The picking method presented has the great advantage of being simple, affordable and accessible for the experienced specialists to graduate students working in the field of micropalaeontology. Very small-scale morphological, crystallographic and geochemical studies of nannofossils have been developed in recent years alongside the improvement of analytical techniques. We hope this new protocol will accelerate the growing interest of micropalaeontologists in single specimen analysis.

\section{Acknowledgements and Funding}

We thank the ESRF scientific committee for selecting and funding the EC-811 experiment which needed a new protocol of nannofossil separation from the matrix. We are particularly grateful to Isabelle Daniel for scientific support, Christophe Chamot at PLATIM (ENS Lyon) for methodological help and to Polymicro Technologies ${ }^{\mathrm{TM}}$ who supplied us with free capillaries during the early phase of the protocol design. We finally thank the associate editor Emanuela Mattioli and reviewers Silvia Gardin and Tom Dunkley Jones for their constructive comments on the manuscript.

\section{Scientific editing by Emanuela Mattioli}

\section{References}

Blanco-Ameijeiras, S., Lebrato, M. et al. 2012. Removal of organic magnesium in coccolithophore calcite. Geochimica et Cosmochimica Acta, 89, 226-239.

Bown, P.R. 1998. Calcareous Nannofossil Biostratigraphy. Chapman \& Hall (Kluwer Academic Publishers), Dordrecht.

Bown, P.R. \& Young, J.R. 1998. Technique. In: Bown, P.R. (ed.) Calcareous Nannofossil Biostratigraphy. British Micropalaeontological Society Publication, Chapman \& Hall (Kluwer Academic Publishers), Dordrecht, 16-28.
Halloran, P.R., Rust, N. \& Rickaby, R.E.M. 2009. Isolating coccoliths from sediment for geochemical analysis. Geochemistry, Geophysics, Geosystems, 10, Q03001.

Henriksen, K., Stipp, S.L.S., Young, J.R. \& Bown, P.R. 2003. Tailoring calcite: Nanoscale AFM of coccolith biocrystals. American Mineralogist, 88, 2040-2044.

Hoffmann, R., Kirchlechner, C., Langer, G., Wochnik, A.S., Griesshaber, E., Schmahl, W.W. \& Scheu, C. 2015. Insight into Emiliania huxleyi coccospheres by focused ion beam sectioning. Biogeosciences, 12, 825-834.

Minoletti, F., Hermoso, M. \& Gressier, V. 2009. Separation of sedimentary micron-sized particles for palaeoceanography and calcareous nannoplankton biogeochemistry. Nature Protocols, 4, 14-24.

Prentice, K., Dunkley Jones, T., Lees, J., Young, J.R., Bown, P.R., Langer, G. Fearn, S. \& EIMF 2014. Trace metal $(\mathrm{Mg} / \mathrm{Ca}$ and $\mathrm{Sr} / \mathrm{Ca})$ analyses of single coccoliths by Secondary Ion Mass Spectrometry. Geochimica et Cosmochimica Acta, 146, 90-106.

Rickaby, R.E.M., Belshaw, N., Kilburn, M., Taylor, A., Grovenor, C. \& Brownlee, C. 2004. Submicron-scale coccolith chemistry revealed by NanoSIMS. Geochimica et Cosmochimica Acta, 68, A215.

Saruwatari, K., Ozaki, N., Nagasawa, H. \& Kogure, T. 2008. Comparison of crystallographic orientations between living (Emiliania huxleyi and Gephyrocapsa oceanica) and fossil (Watznaueria barnesiae) coccoliths using electron microscopes. American Mineralogist, 93, 1670-1677.

Siesser, W.G. 1977. Chemical composition of calcareous nannofossils. South African Journal of Science, 73, 283-285.

Stoll, H.M. \& Shimizu, N. 2009. Micropicking of nannofossils in preparation for analysis by secondary ion mass spectrometry. Nature Protocols, 4, 1038-1043.

Stoll, H.M. \& Ziveri, P. 2002. Separation of monospecific and restricted coccolith assemblages from sediments using differential settling velocity. Marine Micropaleontology, 46, 209-221.

Stoll, H.M., Encinar, J.R., Alonso, J.I.G., Rosenthal, Y., Probert, I. \& Klaas, C. 2001. A first look at paleotemperature prospects from $\mathrm{Mg}$ in coccolith carbonate: Cleaning techniques and culture measurements. Geochemistry, Geophysics, Geosystems, 2, $2000 \mathrm{GC} 000144$.

Stoll, H.M., Shimizu, N., Arevalos, A., Matell, N., Banasiak, A. \& Zeren, S. 2007. Insights on coccolith chemistry from a new ion probe method for analysis of individually picked coccoliths. Geochemistry, Geophysics, Geosystems, 8, Q06020.

Suchéras-Marx, B., Giraud, F., Simionovici, A., Daniel, I. \& Tucoulou, R. 2016. Prospects for new heterococcolith geochemical proxies from high-resolution X-ray fluorescence mapping. Geobiology, 14, 390-403, http://doi.org/ 10.1111/gbi.12177

Winter, A., Jordan, R.W. \& Roth, P.H. 1994. Biogeography of living coccolithophores in ocean waters. In: Winter, A. \& Siesser, W.G. (eds) Coccolithophores. Cambridge University Press, Cambridge, 161-178. 